\title{
Design of Output Power Control Systems based on Mass Flow Rate Comparison of Air-Fuel Ratio (AFR) on Dual Fuel Generator Set by using the PID Control Method
}

\author{
Arief Abdurrakhman ${ }^{1 *}$, Totok Soehartanto ${ }^{1}$, Herry Sufyan Hadi ${ }^{1}$, Mohammad Berel Toriki ${ }^{2}$, \\ Bambang L. Widjiantoro ${ }^{2}$, Bambang Sampurno ${ }^{3}$ \\ ${ }^{1}$ Department of Instrumentation Engineering, Institut Teknologi Sepuluh Nopember, Kampus ITS Sukolilo, \\ Surabaya 60111, Indonesia \\ ${ }^{2}$ Department of Engineering Physics, Institut Teknologi Sepuluh Nopember, Kampus ITS Sukolilo, Surabaya \\ 60111, Indonesia \\ ${ }^{3}$ Department of Industrial Mechanical Engineering, Institut Teknologi Sepuluh Nopember, Kampus ITS Sukolilo, \\ Surabaya 60111, Indonesia
}

\begin{abstract}
Currently, biogas as an alternative fuel has been widely used in the community, including in lamps and biogas stoves. There has been a surplus of biogas in some production regions due to a relatively small need for biogas fuel. So that most biogas users utilize the surplus to become generator fuel. Yet, in the application there is a drawback, namely the instability of the electric power generated per unit time. This is caused by not achieving the optimal water-fuel ratio because the volume of biogas production from the reactor is fluctuating based on the volume of raw material, such as processed cow dung. Therefore, a control method using a PID Controller is constructed to determine the best value of the AFR on a dual fuel generator. The objective is to generate an optimal output of electric power. The generator set is a tool used to generate energy or electrical power. The electric power generated by the generator set used to supply the electrical loads in this research are lamps. Power produced by a generator set ranges from 100 to 1200 watts. The power generated by the generator set is affected by a mixture of air and fuel. The generator set is dual fuel. From the results of this study, a stable response with an overshoot value is below $0 \%$ and its error is $2 \%$. In addition, the best-obtained value of the AFR is 15.06. Furthermore, the stability of the power generated by the generator set is also influenced by the flow rate mass of the fuel injected into the combustion chamber. From the simulation results, when given a power set point at 1200 watts, the obtained value of the air mass flow rate is $0.03754 \mathrm{~kg} / \mathrm{s}$, the mass flow rate of biogas is 0.002367 $\mathrm{kg} / \mathrm{s}$, and the gasoline constant mass flow rate is $0.000125 \mathrm{~kg} / \mathrm{s}$. Meanwhile, when given a set point of 100 watts and a value of $0.009928 \mathrm{~kg} / \mathrm{s}$ air mass flow rate is injected into the chamber, the mass flow rate of biogas is $0.0005341 \mathrm{~kg} / \mathrm{s}$, and the mass flow rate of gasoline is $0.000125 \mathrm{~kg} / \mathrm{s}$. In this research, the value of AFR for complete combustion on a dual fuel system is 15.06 . The results have shown that the PID Controller has been successfully implemented to regulate AFR, and the generator output of power can be constant.
\end{abstract}

Keywords: $\quad$ Air ruel ratio; Biogas; Generator; PID control system

\section{Introduction}

Surges in world oil prices are caused by the rising costs of fossil fuels. On the 
other hand, global environmental issues that demand high levels of environmental quality encourage various energy experts to develop more environmentally friendly energy and support sustainable energy supply security. Currently, fossil fuel energy reserves are nearly depleted and it is difficult to research new sources. Moreover, in 2030, Indonesia will truly become a net importer of energy because a balance between production and domestic energy consumption will occur. Starting this year, the production of domestic energy (fossil fuel and renewable energy) is no longer able to meet domestic consumption, and Indonesia has changed its status to a net importer of energy (BPPT, 2015).

This means renewable energy development is growing. Indonesia, especially, has huge potential for it. Fossil fuels fulfill a major part of the world's energy demand. Higher demand for energy, depletion of fossil fuels, and environmental impacts are the key motivational factors for exploring alternative energy sources (Khatri and Khatri, 2020). Based on the geographic state, Indonesia is abundant with a high amount of energy resources, ranging from hydro, geothermal, biomass, solar, wind, and oceanic sources. Unfortunately, such property has not been widely used as energy sources that could replace the fossil fuel-based energy sources that are nearly depleted. Renewable energy resources are increasingly being used to cover the electricty grid demands in many countries. A current theoretical question that is interesting in terms of introducing a long-term perspective, pertains to what an energy supply from exclusively renewable energy resources could look like. Amounts of fuel from bioenergy are assumed to be annually available. This amount is derived from a study on bioenergy from agricultural waste conducted by GIZ (Günther, 2018). The development of biogas in Indonesia is still relatively slow due to various factors, ranging from people who are still not comfortable with dirt as an energy source to biogas purification problems and the implementation of the generator set (Abdurrakhman \& Soehartanto, 2014). Nowadays, in many industrialized countries, the conversion of municipal organic or solid waste to biogas has become popular in recent years as a sustainable technology that can produce green energy and electricity (Tetteh et al., 2018). In Indonesia, biomass generally has the potential to be used for long-term balancing of society's demand. The biomass itself can be stored for a certain amount of time and place, and the secondary energy carrier (e.g., biogas) can be stored for a very long time (Günther, 2018). Currently, the Indonesian government has been anticipating the development of Distributed Renewable Energy Generation (DREG) using environmentally friendly energy sources for local electrical energy supplies and has developed local sources of renewable energy (Nazir et al., 2016).

Based on data from the Directorate General of Livestock and Animal Health, the number of beef cattle in 2015 reached 15 million. One cow is able to produce manure $23.6 \mathrm{~kg}$ of solid waste a day and $9.1 \mathrm{~kg}$ or liquid waste a day (Setiawan, 2002). One kg of cow or buffalo manure can produce 0.023 to $0.040 \mathrm{~m}^{3}$ of biogas (Stewart et al., 2007). The process of biogas production depends many factors in environment (Abdurrakhman et al., 2018). Therefore, the maximum potential value of biogas produced by manure is as high as 14.16 million $\mathrm{m}^{3} /$ day. The methane amount is 9,912 million $\mathrm{m}^{3} /$ day and $\mathrm{CO}^{2}$ is 4,248 million $\mathrm{m}^{3} /$ day. In other words, within a year, Indonesia will contribute 1.55 billion $\mathrm{m}^{3} \mathrm{CO}_{2}$ or the equivalent of 2.77 million tons per year. Indonesia will also contribute the amount of 3.617 billion $\mathrm{m}^{3}$ methane, equivalent to 6,466 million tons per year. The effect of methane gas is equivalent to 21 times the $\mathrm{CO}_{2}$ of greenhouse gases. The contribution of methane gas will be equivalent to 135.8 million tons of $\mathrm{CO}_{2}$ per year. It means that by the addition of these gasses in the atmosphere, methane gas is equivalent to 135.8 million tons worth of $\mathrm{CO}_{2}$ gasses a year. Levels of $\mathrm{H}_{2} \mathrm{~S}$ contained in the biogas can be harmful to users because at levels 
of more than 500 ppm, biogas can cause lung damage and even lead to death (Noyola et al., 2006).

Currently, several biogas purification methods have been developed. The methods are absorption, adsorption, cryogenic, membrane, and carbon mineralization technology (O'Brien, 1991). Literally, the gas-liquid absorption method with a water scrubber system is a priority among biogas purification applications because its main ingredient is water, which can be relatively cheap, available, and environmentally friendly (Budzianowski et al., 2017). If water temperature is between $10-20^{\circ} \mathrm{C}, \mathrm{CO}_{2}$ gas solubility level is between 2.5 to $1.6 \mathrm{~g}$ per $\mathrm{kg}$ of liquid gas. Meanwhile, within the same temperature range, it will be able to dissolve the $\mathrm{H}_{2} \mathrm{~S}$ gas at 5.5 to $3.9 \mathrm{~g}$ per $\mathrm{kg}$ of liquid gas (Medard, 1976).

A dual fuel generator set is a standard gasoline engine with biogas fuel added in its combustion chamber. The engine's ignition is powered by a gas spray called pilot fuel. In other words, liquid or gaseous fuels can be injected into the engine by making a hole in the intake manifold of the engine itself. When the type of added fuel typs is liquid, such as ethanol or methanol, carburetor is added to the system. This makes the fuel pump at a certain pressure and become atomized as the fuel is injected into the air intake. As for the fuel gas, it is not needed anymore since the gas fuel carburetor already has its own pressure (Setiawan, 2002). Hotta et al. (2019) explored the potential of raw biogas as an alternative and standalone fuel for gasoline-fueled spark ignition (SI) engines. A single cylinder spark ignition engine is operated with both gasoline and raw biogas at a compression ratio of 10 under wide open and part-throttle conditions. The baseline test is performed with gasoline, and subsequent experiments are carried out with raw biogas. The engine performance, combustion, and emission parameters are measured over a range of speed variations (1450-1700 rpm). A comparative analysis of the result showed $18 \%$ of reduction in brake power, $66 \%$ increase in brake specific fuel consumption, and $12 \%$ reduction in brake thermal efficiency when the engine is fueled with raw biogas. Ambarita et al. (2017) concluded that the output power and specific fuel consumption of the Compression Ignition (CI) engine ran in dual-fuel mode are higher than the CI engine ran in pure diesel mode. The brake thermal efficiency of the CI engine ran in dual-fuel mode was strongly affected by the biogas flow rate and methane concentration. An optimum biogas flow rate for a maximum brake thermal efficiency exists. The biogas can reduce the diesel fuel consumption significantly.

A dual fuel system's advantages include conserving the use of gasoline as fuel, production costs that can be minimized, and generator set modification costs are relatively cheaper than converting to a whole gas engine. Furthermore, the application of biogas with a dual fuel system on the generator set can improve the performance and efficiency of the engine (Bastida et al., 2017). The utilization of a biogas generator set will not change the composition of machine tools and only add to the system equipment, such as a mixer venturi on the suction channel. The use of dual fuel intended to reduce the use of gasoline in the combustion process would entail a partial substitution of gasoline by biogas. Verma et al. (2019) performed an experimental investigation on a diesel-biogas dual fuel (DF) engine based on energy and exergy analyses. The analyses included the effects of change in the compression ratio (CR), exhaust gas recirculation (EGR), and EGR temperature on the performance and emission characteristics of a DF engine. The results showed that the highest efficiencies at both low and high loads were obtained with hot EGR cases. At the same time, exhaust emissions could also be kept in check. Mixing biogas as engine fuel was studied by Verma et al. (2017) to determine the effect of variations in the composition of biogas on the performance of diesel engines for dual fuels using exergy analysis. The variation of biogas composition was 93\% (BG93), 84\% (BG84), and 75\% (BG75). The AFR 
produced is 22.47 for BG 93, 16.77 for BG84, and 13.49 for BG75. In another study, de Faria et al. (2017) conducted a thermodynamic model to predict the performance of a spark ignition engine using biogas fuel. Moreover, it was concluded that the increased load results in a higher engine airflow that increases power output at a constant engine speed, which is greater than fuel consumption, resulting in a smaller overall specific fuel consumption (sfc). In addition, the simulation states that spark timing has opposite effects at NOx and sfc levels.

A generator set using a dual fuel system still needs a lot of work in the development phase. One of the items is the generator set's output power controls. The generator set's output power control needs to be designed so that the generator set is able to produce a maximum and stable output of power in accordance with daily electricity needs. In order to make the generator produce a stable output of power for demand, the mass flow rate of fuel and air in the combustion chamber of the engine should be consistent with the required power demand. If more power from the generator's output is required, then the mass flow rate of air and fuel (petrol and biogas) entering the combustion chamber will also be getting bigger. Additionally, the mixture of fuel and air must be in accordance with combustion reaction rules. Therefore, to obtain optimum combustion, the calculation of the AFR is performed by stoichiometric equation.

The main objective of this study is the determination of flow rate values from air, biogas, and gasoline based on the standard AFR value. The results of this study are expected to be utilized by biogas users who will use it as a mixed fuel in the engine to produce electricity. This needs to be analyzed so that the use of biogas can be optimal, especially in certain production areas that leverage livestock manure. In some of these areas, biogas production is usually only used for biogas lamps and stoves, while the rest of the production is not utilized properly, even though electricity demand is relatively high.

The desired design in this system is the value of a stable output of power in accordance with a given load. In this system, there is a non-linear function that is connected between pressure input and output on the throttle valve. For a non-linear system, there are many methods used to control disturbance, feedback stabilization, and performance enhancements, such as research by Humaidi et al. (2019) that uses an extended state observer (ESO). It produced smaller peaking and had immunity against measurement noise and parameter variations. A non-linear controller has also been used to control the angle of the roll channel for delta wing aircraft with the presence of wing rock phenomenon using the Lyapunov method and the zero-convergence with a MATLAB simulation (Humaidi et al., 2019). In some more complex plants, an active disturbance rejection control (IADRC) is needed to overcome disturbances and uncertainties and outperform systems (Najm and Ibraheem, 2020).

Non-linear systems can also use non-linear PID (NPID). The NPID control has been found in two categories of applications: (1) Non-linear systems, where NPID control is used to accommodate the non-linearity, usually to achieve consistent responses across a range of conditions for the system; (2) Linear systems, where NPID control is used to achieve performance not achievable by a linear PID control system, such as increased damping, reduced rise time for step or rapid inputs, and improved tracking accuracy (Su et al., 2005). Non-linear PID controllers are divided into two categories: first, the controller gain is directly related to the magnitude of the state. Second, it uses phases, such as a parameter to modify this controller gain (Abdul-Adheem et al., 2017). In this paper, the PID controller is used to maintain the stability of the power generated by the generator set, and the performance of the control system is analyzed. 


\section{Methods}

The application of biogas in dual fuel mode is an attractive way to promote the efficient utilization of biogas (Qian et al., 2017). This research uses a dual fuel generator set as a research object. The engine is a spark ignition engine with four strokes. Gasoline and biogas are fuel that are used for combustion on the engine's cylinder, while the use of dual fuel is to reduce the use of gasoline in the combustion process. In addition, the injected air into the cylinder chamber aims to achieve complete combustion and optimum power. To inject gasoline, biogas, and air into the combustion chamber, a ratio control algorithm and proportional-integral (PI) controller is used. Ratio control is an algorithm that worked based on a value that was determined by using a dual fuel AFR calculation. A PI controller presents the advantage of integral action, leading to the elimination of the deviation between the asymptotic state and the set point. The response was faster when the gain increased and could become oscillatory. For larger gain values, the behavior may even become unstable. The decreasing integral time constant increases the integral gain and makes the response faster. Because of the integral term, the PI controller may present a windup effect if the control variable $u$ becomes saturated. In this case, the integral term becomes preponderant and needs time to be compensated. It is preferable to use a antiwindup system. The PID controller presents the same interest as the PI with respect to an asymptotic state. Furthermore, the derivative action allows a faster response without needing to choose too high of a gain for the PI controller. This derivative action thus has a stabilizing effect (Marlin, 2000). The best parameters of a fractional-order PID controller consist of proportional gain (KP), integral gain (KI), derivative gain (KD), fractional order of differentiator $\alpha$, and fractional-order of integrator $\lambda$ (Ibraheem and Ibraheem, 2016). PID controllers have been the most commonly used industrial controllers. The classical PID controllers have many advantages like simple design, and gains are easy to adjust with very good robustness (Khatoon et al., 2017). A linear PID controller is usually adequate for a nominal process. However, it often behaves poorly for a process with changes or uncertainties in operating conditions or environmental parameters (Tian et al., 1999). For a non-linear system that ignores heat radiation, the operator theory-based non-linear control method is confirmed to be effective in ensuring robust stability of the controlled system (Jiang et al., 2012). The non-linear PID controllers are classified into two broad classes according to how the state is affecting the gain. In the first class, the controller's gain is directly related to the magnitude of the state. The second class uses the phase of the state as the parameter to modify the gain of these controllers (Abdul-Adheem et al., 2017).

The calculation of the value of AFR is used to determine the ratio between the mass air flow rate and mass flow rate of fuel (petrol and biogas). To obtain the dual fuel AFR value, the following equation is used (Stewart et al., 2007):

$$
A F R_{\text {sto }}=\frac{\left[\alpha\left(x_{d}+\frac{y_{d}}{4}\right)+\beta\left(x_{g}+\frac{y_{g}}{4}\right)\right] M W_{a i r}}{\alpha\left(x_{d} \cdot M W_{c}+y_{d} \cdot M W_{H}\right)+\beta\left(x_{g} \cdot M W_{c}+y_{g} \cdot M W_{H}\right)}
$$

The term $\mathrm{MW}_{\mathrm{C}}$ in Equation 1 is the molecular weight of atom $\mathrm{C} ; \mathrm{MW}_{\mathrm{H}}$ is the molecular weight of atom $\mathrm{H}$; MW air is the molecular weight of air; $\alpha$ is the mass of gasoline to the total mass of fuel; $\beta$ is the mass of biogas to the total mass of fuel; $X_{d}$ is number of atom $C$ in the gas compound; $\mathrm{Yd}$ is the amount of atom $\mathrm{H}$ in the compound of gasoline, and $\mathrm{xg}$ is the amount of atom carbon in the biogas compound. 


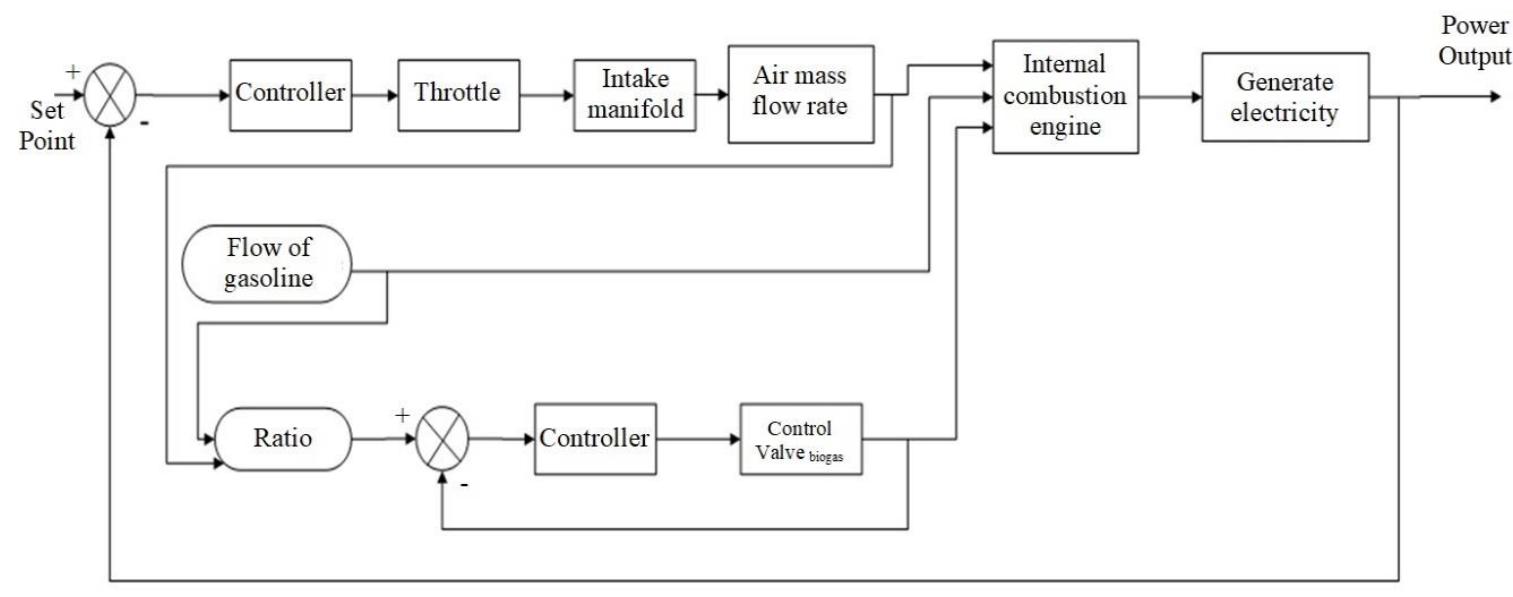

Figure 1 Block diagram of output power control system on a dual fuel generator set

Based on Figure 1, throttle valve is an actuator which regulates the amount of air mass flow in the engine's combustion chamber. To calculate the amount of mass air flow (ideal gas) that passes through the throttle valve, the Bernoulli equate can be used as follows:

$$
q_{i}(t)=C_{d}[1-\cos \cos (u)] \frac{\pi}{4} D^{2} \frac{P_{\text {in }}}{\sqrt{R T_{\text {in }}}} f\left(P_{\text {in }}, P_{\text {out }}\right)
$$

Based on the Equation 2 above, the airflow can be adjusted via the throttle valve opening $(\mathrm{u})$ from $0^{0}$ to $90^{\circ}$. The non-linear function that connects the input pressure and output pressure is as follows.

$$
\left(P_{\text {in }}, P_{\text {out }}\right)= \begin{cases}\sqrt{k\left[\frac{2}{k+1}\right]^{\frac{k+1}{k-1}}} & P_{\text {out }} \leq P_{\text {cr }} \\ {\left[\frac{P_{\text {out }}}{P_{\text {in }}}\right]^{\frac{1}{k}} \sqrt{\frac{2 k}{k-1}\left[1-\left(\frac{P_{\text {out }}}{P_{\text {in }}}\right) \frac{k-1}{k}\right]}} & P_{\text {out }} \geq P_{\text {cr }}\end{cases}
$$

$\mathrm{P}_{\text {in }}$ is pressure in the intake manifold $(\mathrm{Pa}) ; \mathrm{P}_{\mathrm{cr}}$ is supersonic flow in the intake manifold $(\mathrm{Pa})$ and $\mathrm{P}_{\text {out }}$ is pressure out from the intake manifold $(\mathrm{Pa})$.

A mathematical modeling of the intake manifold's subsystems can be approximated using the ideal gas equation as follows:

$$
\begin{aligned}
& \frac{d}{d t} m(t)=\dot{m}_{\text {in }}(t)-\dot{m}_{\text {out }}(t) \\
& \frac{d}{d t} U(t)=\dot{H}_{\text {in }}(t)-\dot{H}_{\text {out }}(t)
\end{aligned}
$$

It is assumed that the fluid flow is modeled using the ideal gas equation as follows:

$$
p(t) . V=m(t) \cdot R \cdot \vartheta(t)
$$

When connected with a caloric value:

$$
\begin{gathered}
U(t)=c_{v} \cdot \vartheta(t) \cdot m(t) \\
\dot{H}_{\text {in }}(t)=c_{p} \cdot \vartheta_{\text {in }}(t) \cdot \dot{m}_{\text {in }}(t) \\
\dot{H}_{\text {out }}(t)=c_{p} \cdot \vartheta(t) \cdot \dot{m}_{\text {out }}(t)
\end{gathered}
$$

Substitution into equation:

$$
\frac{d}{d t} p(t)=\frac{k \cdot R}{V}\left[\dot{m}_{\text {in }}(t) \cdot \vartheta_{\text {in }}(t)-\dot{m}_{\text {out }}(t) \cdot \vartheta(t)\right]
$$




$$
\begin{gathered}
\frac{d}{d t} \vartheta=\frac{\vartheta \cdot R}{p \cdot V \cdot c_{v}}\left[c_{p} \cdot \dot{m}_{\text {in }} \cdot \vartheta_{\text {in }}-c_{p} \cdot \dot{m}_{\text {out }} \cdot \vartheta-c_{v}\left(\dot{m}_{\text {in }}-\dot{m}_{\text {out }}\right) \cdot \vartheta\right] \\
\frac{d}{d t} p(t)=\frac{R \cdot \vartheta(t)}{V} \cdot\left[\dot{m}_{\text {in }}(t)-\dot{m}_{\text {out }}(t)\right. \\
\frac{d}{d t} P_{m}=K_{m}\left(\dot{m}_{a i}-\dot{m}_{a o}\right)(\mathrm{T})=\frac{R \cdot T_{m}(t)}{V_{m}}\left(\dot{m}_{a i}-\dot{m}_{a o}\right)(t)
\end{gathered}
$$

where $\mathrm{P}_{\mathrm{m}}$ is the rate of change of manifold pressure (bar/s); $\dot{m}_{a i}$ is the mass flow rate of air entering the manifold (kg/s); $\dot{m}_{a o}$ is mass flow rate of air out through manifold $(\mathrm{kg} / \mathrm{s})$ and $V_{\mathrm{m}}$ is manifold volume $\left(\mathrm{m}^{3}\right)$.

After a through intake manifold, air will enter to the combustion chamber or cylinder. Engine mass flow is the air mass flow that is injected into the combustion chamber with the calculation's air pressure in a part of the intake manifold. Based on the air system, the engine characteristics can be assumed to be a volumetric pump. Additionally, the amount of mass air flow needed for combustion in the cylinder can be defined based on the speeddensity equation (Bastida et al., 2017).

$$
q_{c y l}=\frac{\eta_{v} P_{o u t} V_{d} \omega}{2 \pi N R T}
$$

The term $\mathrm{q}_{\text {cyl }}$ in Equation 15 is the air flow rate that becomes the mass flow rate injected into the engine cylinder $(\mathrm{kg} / \mathrm{s})$ and is always changing the appropriate load of the generator.

A modern fuel injection system is set up so that the comparison mass air flow rate and fuel mass flow rate is kept constant to achieve volumetric efficiency without changes. The density and mass air flow measurement are used to control the injected fuel. The power the engine generates is obtained with the following equation (Bastida et al., 2017):

$$
P=\frac{\eta_{c} \eta_{v} P_{\text {out }} V_{d} \omega H\left(\frac{F}{A}\right)}{2 \pi N R T_{\text {in }}}
$$

In Equation 16, $\eta_{c}$ is the efficiency of combustion (\%); $\eta_{c}$ is volumetric efficiency in the cylinder (\%); $\mathrm{T}_{\text {in }}$ is temperature input of air $(\mathrm{K})$ and $\mathrm{Vd}$ is displacement of the piston in the cylinder $\left(\mathrm{m}^{3}\right)$.

In a spark-ignited engine, the combustion process occurs because there is a mixture of fuel. In this case, the mixture is gas and biogas with air in the cylinder engine and ignited by a spark plug, causing sparks and combustion as described in the previous chapter. The combustion process will drive the piston and crankshaft so that it will turn a generator to the torque produced by the engine speed and can produce power. This is the torque equation generated from the combustion of the AFR, according to the stoichiometric equation (Bastida et al., 2017):

$$
\begin{aligned}
\dot{\omega} & =\frac{1}{J}\left[\left(T_{m}-T_{e}\right)-b \omega\right] \\
& =\frac{1}{J}\left[\left(\frac{\eta_{c} \eta_{v} \eta_{e} P_{\text {out }} V_{d} H\left(\frac{F}{A}\right)}{2 \pi N R T_{\text {in }}}-T_{e}\right)-b w\right]
\end{aligned}
$$

\section{Results and Discussion}

\subsection{Relation between Power and Mass Flow Rate}

The relation between power and the mass flow rate is shown in Figure 4 and Figure 5 . Air and fuel mass flow rate will increase relative to increases in power requirements. The engine requires a greater supply of energy to produce a greater output of power. The most substantial change of air mass flow rate and biogas is with the change of 100 watts to 200 
watts, producing a value of $0.259 \mathrm{~kg} / \mathrm{s}$ and $0.018 \mathrm{~kg} / \mathrm{s}$, respectively. The slightest changes from in the mass flow rate of air and biogas is when 1100 watts changes to 1200 watts with a value of $0.093 \mathrm{~kg} / \mathrm{s}$ and $0.007 \mathrm{~kg} / \mathrm{s}$, respectively.

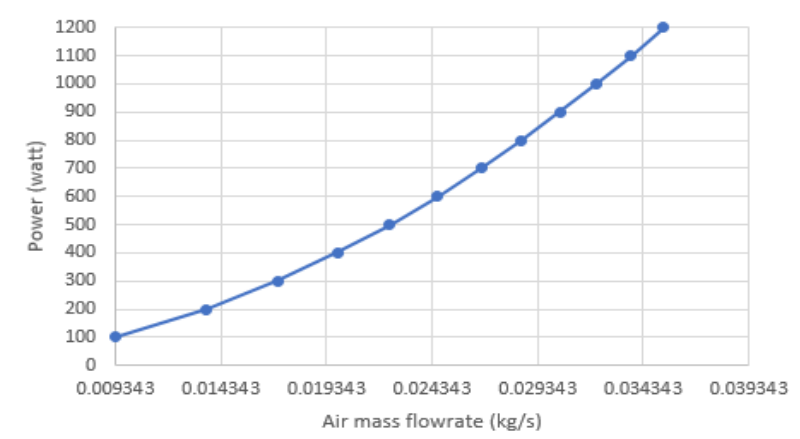

Figure 2 Relation graph between power and air mass flow rate

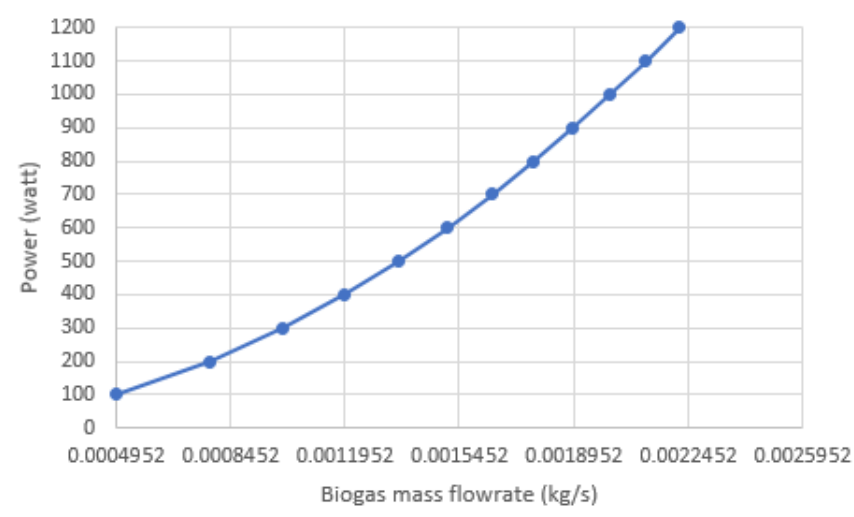

Figure 3 Relation graph between power and biogas mass flow rate

\subsection{Tracking with Increase $10 \%$ of Set Point}

Tracking to specify a frequency-domain tracking requirement between specified inputs and outputs. This tuning goal specifies the maximum relative error (gain from reference input to tracking error) as a function of frequency. In this case, tracking is raising $10 \%$ of the set point. The change of set point values is obtained for a settling time (Ts) is $1.45 \mathrm{sec}$, a rise time ( $\mathrm{Tr}$ ) is 1.45 seconds, delay time (Td) is 0.01 seconds, maximum overshoot (Mp) is $0 \%$, and an error steady state (Ess) is $0 \%$. The combined value of the rise time and settling time, for the first time, reached a direct set point of system stability. This test indicates that a change of set points is possible, followed by process variables. The results of tracking increase $10 \%$ of the set point is shown in Figure 6.

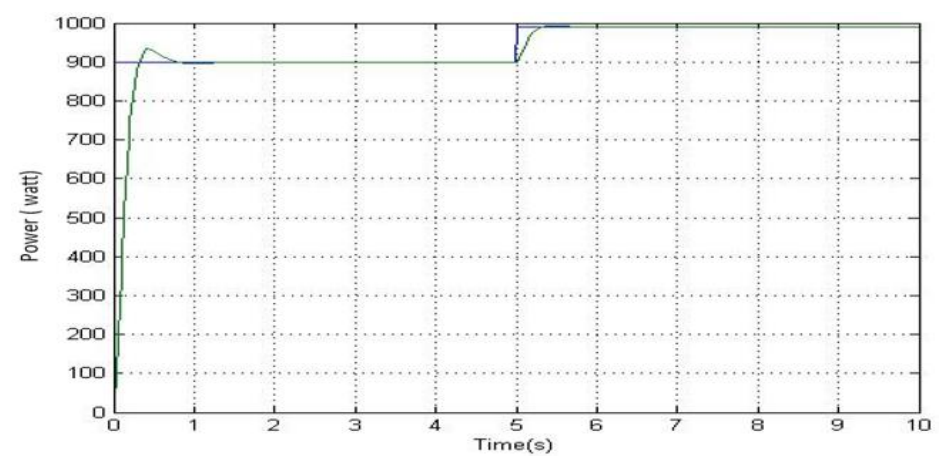

Figure 4 Graph of output power response with tracking with increase $10 \%$ of the set point 


\subsection{Tracking with Decrease 10\% of Set Point}

In the testing of the set point, tracking also lowers it by $10 \%$. The changes in set point values are obtained for a settling time (Ts) is 0.7 seconds, a rise time (Tr) is 0.7 seconds, delay time (Td) is 0.005 seconds, a maximum overshoot (Mp) is $0 \%$, and an error steady state (Ess) is $0 \%$. The combined value of the rise and settling time, for the first time, reached a direct set point of system stability. This test indicates that a change of the set point is possible, followed by process variables. The results of tracking decrease $10 \%$ of the set point is shown in Figure 7.

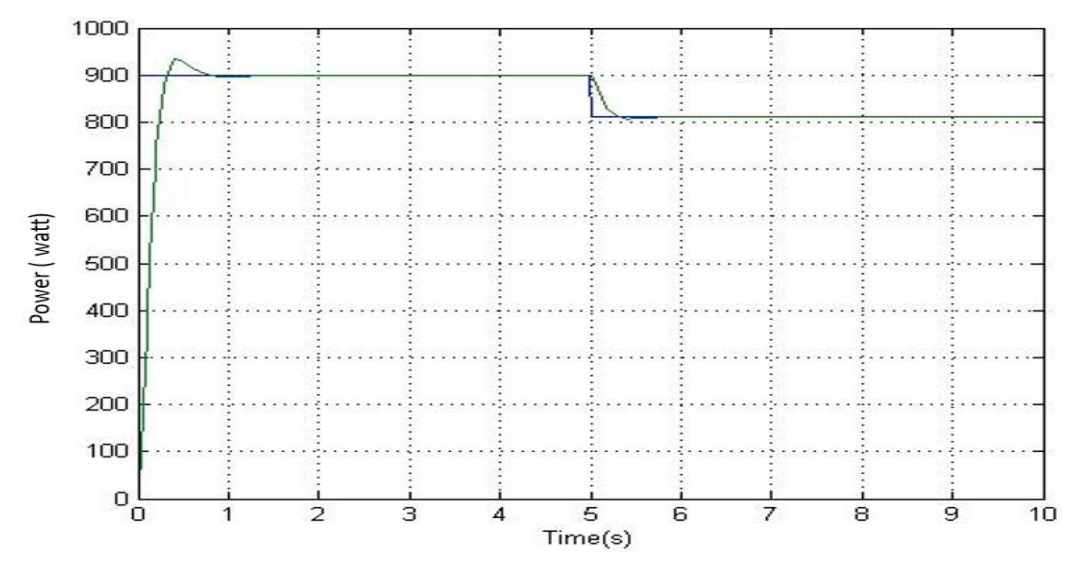

Figure 5 Graph of Output Power Response with Tracking with Decrease 10\% of the Set Point

\subsection{Results of System Modeling}

The results of modeling in Simulink MATLAB R2013b must be tested by input the value of set points that require power ranges between 100-1200 watts. If more power is required, the mass air flow rate and biogas will be increased as well, but the mass flow rate of gas in this study is constant.

Table 1 Relation between the power and mass flow rate of air and fuel

\begin{tabular}{cccc}
\hline Power (Watt) & $\begin{array}{c}\text { Mass Flow rate of } \\
\text { Gasoline }(\mathrm{kg} / \mathrm{s})\end{array}$ & $\begin{array}{c}\text { Mass Flow rate of } \\
\text { Biogas }(\mathrm{kg} / \mathrm{s})\end{array}$ & $\begin{array}{c}\text { Mass Flow rate of } \\
\text { Air }(\mathrm{kg} / \mathrm{s})\end{array}$ \\
\hline 100 & 0.01 & 0.029 & 0.560 \\
200 & 0.01 & 0.047 & 0.819 \\
300 & 0.01 & 0.060 & 1.022 \\
400 & 0.01 & 0.071 & 1.192 \\
500 & 0.01 & 0.081 & 1.341 \\
600 & 0.01 & 0.090 & 1.476 \\
700 & 0.01 & 0.098 & 1.601 \\
800 & 0.01 & 0.106 & 1.716 \\
900 & 0.01 & 0.113 & 1.825 \\
1000 & 0.01 & 0.120 & 1.928 \\
1100 & 0.01 & 0.126 & 2.025 \\
1200 & 0.01 & 0.133 & 2.118 \\
\hline
\end{tabular}

Table 1 depicts the relation between the power and mass flow rate. The more power that is required, the more air and fuel will need to increase. This is because the engine requires a greater supply of energy to produce a greater output power. The most substantial change of air mass flow rate and biogas occurs when the set point changes from 100 watts to 200 watts with a value of $0.259 \mathrm{~kg} / \mathrm{s}$ and $0,018 \mathrm{~kg} / \mathrm{s}$, respectively. The slightest 
changes from the air mass flow rate and biogas occur when the power set point changes from 1100 watts to 1200 watts with a value of $0.093 \mathrm{~kg} / \mathrm{s}$ and $0.007 \mathrm{~kg} / \mathrm{s}$, respectively.

Table 2 Validation of the mass flow rate of biogas

\begin{tabular}{ccc}
\hline Power (Watt) & $\begin{array}{c}\text { Mass Flow rate of Biogas (Simulation) } \\
\mathrm{kg} / \mathrm{s}\end{array}$ & $\begin{array}{c}\text { Mass Flow rate of Biogas } \\
\text { (Real Plan) } \mathrm{kg} / \mathrm{s}\end{array}$ \\
\hline 100 & 0.029 & 0.032 \\
200 & 0.047 & 0.049 \\
300 & 0.060 & 0.064 \\
400 & 0.071 & 0.075 \\
500 & 0.081 & 0.086 \\
600 & 0.090 & 0.095 \\
700 & 0.098 & 0.103 \\
800 & 0.106 & 0.111 \\
900 & 0.113 & 0.117 \\
1000 & 0.120 & 0.125 \\
1100 & 0.126 & 0.133 \\
1200 & 0.133 & 0.142 \\
\hline
\end{tabular}

Table 3 Validation of mass flow rate of air

\begin{tabular}{ccc}
\hline Power (Watt) & Air Mass Flow rate (Simulation) kg/s & $\begin{array}{c}\text { Air Mass Flow rate } \\
\text { (Real Plan) kg/s }\end{array}$ \\
\hline 100 & 0.560 & 0.601 \\
200 & 0.819 & 0.871 \\
300 & 1.022 & 1.092 \\
400 & 1.192 & 1.255 \\
500 & 1.341 & 1.419 \\
600 & 1.476 & 1.571 \\
700 & 1.601 & 1.682 \\
800 & 1.716 & 1.789 \\
900 & 1.825 & 1.896 \\
1000 & 1.928 & 1.995 \\
1100 & 2.025 & 2.099 \\
1200 & 2.118 & 2.224 \\
\hline
\end{tabular}

Table 2 represents the relation of the mass flow rate of fuel in simulated and real plant results with certain power values. Table 3 depicts the relation of the mass air flow rate in simulated and real plant results during certain power values. From these data, it appears that when greater outputs of power are required, then the mass flow rate of fuel and air will also increase. The relation between power, mass flow rate of fuel, and mass flow rate of air are comparable. However, there are differences between the mass flow rate of fuel and air in simulated and real scenarios. This is due to the results of the simulation including several engine parameters under ideal conditions, such as pressure on the intake manifold.

In some of the above tables, the PID Controller that is applied to this system can be used as a reference in determining the values of air, biogas, and gasoline flow rate needed to reach the standard AFR value. When the AFR value has reached the standard, the stability of the output power generated by an engine with a dual fuel system (gasoline-biogas) will be even higher. 


\section{Conclusions}

Based on the results of this research, a stable output power response occurs with an overshoot maximum value that average below $20 \%$ and an error value below $2 \%$ in each of the set point values between 100-1200 watts. In addition, the PID parameter values are Kp $=120, \mathrm{Ki}=0.1$, and $\mathrm{Kd}=15.2$. The PID parameter values for the flow rate control of biogas are $\mathrm{Kp}=5, \mathrm{Ki}=3$, and $\mathrm{Kd}=1$. In addition, there is a difference between the simulated and real scenario mass flow rates, with the average biogas mass flow rate of $6.94 \%$ and the mass air flow rate at $7.36 \%$. The amount of power generated by generator set and the mass flow rate of air and fuel will increase. For the maximum power of 1200 watts, the obtained air mass flow rate amounted to $2.118 \mathrm{~kg} / \mathrm{s}$, the mass flow rate of biogas amounted to 0.133 $\mathrm{kg} / \mathrm{s}$, and the gasoline mass flow rate amounted to $0.01 \mathrm{~kg} / \mathrm{s}$. For the minimum power, the obtained air mass flow rate amounted to $0.560 \mathrm{~kg} / \mathrm{s}$, the mass flow rate of biogas amounted to $0.029 \mathrm{~kg} / \mathrm{s}$, and the gas mass flow rate amounted to $0.01 \mathrm{~kg} / \mathrm{s}$. In this research, the value of the AFR for complete combustion on a dual fuel system is 15.06 . The results have shown that the PID Controller can be successfully implemented to regulate AFR, and the generator's output power can be constant.

\section{Acknowledgements}

This study was made possible with the help of KPSP Setia Kawan Nongkojajar, Pasuruan, Testing and Calibration Laboratory, Industrial Instrumentation Laboratory, and the Department of Instrumentation Engineering ITS as data providers. The authors would like to thank the Directorate of Research and Community Service Institut Teknologi Sepuluh Nopember through Contract No. 1386/PKS/ITS/2018 for funding this research in 2018.

\section{References}

Abdul-Adheem, W.R., Ibraheem, I.K., 2017. From PID to Nonlinear State Error Feedback Controller. International Journal of Advanced Computer Science and Applications, Volume 8(1), pp. 312-322

Abdurrakhman, A., Soehartanto, T., 2014. Analisis Karakterisasi Water Scrubber pada Alat Purifikasi Biogas Tipe Kombinasi Spray Tower dan Tray Tower (Analysis of Water Scrubber Characterization in Biogas Purification System for Combination Type of Spray Tower and Tray Tower). In: National Seminar of Applied Technology, Universitas Gadjah Mada, Yogyakarta

Abdurrakhman, A., Adhim, M.M., Widjiantoro, B.L., 2018. Optimization of $\mathrm{H}_{2} \mathrm{~S}$ Absorption Toward the Alteration in Flow Rate of Biogas Purification System with Water Scrubber using Particle Swarm Optimization. In: AIP Conference Proceeding, Volume 1983(1)

Ambarita, H., 2017. Performance and Emission Characteristics of a Small Diesel Engine Run in Dual-Fuel (Diesel-Biogas) Mode. Case Studies in Thermal Engineering, Volume 10, pp. 179-191

Bastida, H., Carlos, E., Abeyesekerra, M., 2017. Dynamic Modelling and Control of a Reciprocating Engine. Energy Prodia, Volume 142, pp. 1282-1287

Budzianowski, W.M., Wylock, C.E., Marciniak, P.A., 2017. Power Requirements of Biogas Upgrading by Water Scrubbing and Biomethane Compression: Comparative Analysis of Various Plant Configurations. Energy Conversion and Management, Volume 141, pp. 219 
de Faria, M.M.N., Bueno, V.M., Ayad, E., Belchior, P., 2017. Thermodynamic Simulation Model for Predicting the Performance of Spark Ignition Engines using Biogas as Fuel. Journal of Energy Conversion and Management, Volume 149, pp. 1096-1108

Günther, M., 2018. Challenges of a 100\% Renewable Energy Supply in the Java-Bali Grid. International Journal of Technology, Volume 9(2), pp. 257-266

Hotta, S.K., Sahoo, N., Mohanty, K., 2019. Comparative Assessment of a Spark Ignition Engine Fueled with Gasoline and Raw Biogas. Renewable Energy, Volume 134, pp. 1307-1319

Humaidi, A.J., Ibraheem, I.K., 2019. Speed Control of Permanent Magnet DC Motor with Friction and Measurement Noise using Novel Nonlinear Extended State Observerbased Anti-disturbance Control. Energies, Volume 12, pp. 2-22

Humaidi, A.J., Hameed, A.H., Ibraheem, I.K., 2019. Design and Performance Study of Two Sliding Mode Backstepping Control Schemes for Roll Channel of Delta Wing Aircraft. In: The $6^{\text {th }}$ International Conference on Control, Decision and Information Technologies (CoDIT), Paris, France, pp. 1215-1220

Ibraheem, I., Ibraheem, G, 2016. Motion Control of an Autonomous Mobile Robot using Modified Particle Swarm Optimization Based Fractional Order PID Controller. Engineering and Technology Journal, Volume 34(13), Part (A) Engineering, pp. 24062419

Jiang, J., Kaigala, G., Marquez, H., 2012. Nonlinear Controller Designs for Thermal Management in PCR amplification. In: IEEE Transactions on Control Systems Technology, Volume 20(1), pp. 11-30

Khatoon, S., Nasiruddin, I., Shahid, M., 2017. Design and Simulation of a Hybrid PD-ANFIS Controller for Attitude Tracking Control of a Quadrotor UAV. Arabian Journal for Science and Engineering, Volume 42, pp. 5211-5229

Khatri, N., Khatri, K.K., 2020. Hydrogen Enrichment on Diesel Engine with Biogas in Dual Fuel Mode. International Journal of Hydrogen Energy, Volume 45(11), pp. 7128-7140

Marlin, T.E., 2000. Process Control: Designing Processes and Control Systems for Dynamic Performance. Boston: McGraw-Hill

Medard, L., 1976. Gas encyclopaedia. Elsevier Science

Najm, A.A., Ibraheem, I.K., 2020. Altitude and Attitude Stabilization of UAV Quadrotor System using Improved Active Disturbance Rejection Control. Arabian Journal for Science and Engineering, Volume 45, pp. 1985-1999

Nazir, R., Nurdin, M., Fitrianto, E., 2016. Voltage Profile Improvement of the $20 \mathrm{kV}$ Painan Distribution System with Multiple Distributed Renewable Energy Generation. International Journal of Technology, Volume 7(1), pp. 26-37

Noyola, A., Morgan-Sagastume, J.M., López-Hernández, J.E., 2006. Treatment of Biogas Produced in Anaerobic Reactors for Domestic Wastewater: Odor Control and Energy/Resource Recovery. Reviews in Environmental Science and Bio/Technology, Volume 5, pp. 93-114

O’Brien, M., 1991. Catalytic Oxidation of Sulfides in Biogas, Ventilation Air and Wastewater Streams from Anaerobic Digesters. In: Proceedings 1991 Food Industry Environment Conference, USA

Qian, Y., Sun, S., Ju, D., Shan, X., Lu, X., 2017. Review of the State-of-the-Art of Biogas Combustion Mechanisms and Applications in Internal Combustion Engines. Renewable and Sustainable Energy Reviews, Volume 69, pp. 50-58

Setiawan, A.I, 2002. Harnessing the Livestock Manure Utilization Problem Solution Environment and Alternative Energy. Swadya, Jakarta: Third Printing Spreaders 
Stewart, J., Clarke, A., Chen, R., 2007. An Experimental Studyof the Dual-fuel Performance of a Small Compression Ignition Diesel Engine Operating with Three Gaseous Fules rid a-2785-2010. In: Proceedings of the Institution of Mechanical Engineers Part D, 221 (D8), pp. 943-956

$\mathrm{Su}$, Y.X., Sun, Dong, Duan, B.Y., 2005. Design of an Enhanced Nonlinear PID Controller. Mechatronics, Volume 15(8), pp.1005-1024

Tetteh, E., Amano, K.O.A., Asante-Sackey, D., Armah, E., 2018. Response Surface Optimization of Biogas Potential in Co-digestion of Miscanthus Fuscus and Cow Dung. International Journal of Technology, Volume 9(5), pp. 944-954

The Agency for the Assessment and Application of Technology (BPPT), 2015. Energy Development to Support Sustainable Development, Indonesia Energy Outlook

Tian, Y.C., Tadé, M.O., Tang, J., 1999. A Nonlinear PID Controller with Applications. In: IFAC Proceedings Volumes, Volume 32(2), pp. 2657-2661

Verma, S., Das, L.M., Kaushik, Bhatti, S.S., 2019. The Effects of Compression Ratio and EGR on the Performance and Emission Characteristics of Diesel-Biogas Dual Fuel Engine. Applied Thermal Engineering, Volume 150, pp. 1090-1103

Verma, S., Das, L.M., Kaushik, S.C., 2017. Effects of Varying Composition of Biogas on Performance and Emission Characteristics of Compression Ignition Engine using Exergy Analysis. Energy Conversion and Management Journal, Volume 138, pp. 346-359 